\title{
Remote Student Support During COVID-19: Perspectives of Chief Online Officers in Higher Education
}

\author{
Bettyjo Bouchey \\ National Louis University \\ Erin Gratz \\ Orange Coast College \\ Shelley Kurland \\ County College of Morris
}

\begin{abstract}
In order to understand the nature of online student support services during the COVID-19 pandemic, 31 chief online officers representing a range of colleges and universities were interviewed in late Spring 2020. Findings highlighted issues of access and equity in online student support services, the rapid expansion of student services due to the pandemic, and how strength in online programming enabled a more seamless pivot to emergency remote operations. This study adds texture to the literature on the gaps between support services offered to face-to-face versus online students, and also provides a foundation for important questions regarding the future of online student support after COVID-19. The study also begins a dialog into the long-term ramifications of siloing online organizational units at institutions of higher education.
\end{abstract}

Keywords: student support services, student retention services, student tutoring, student advising, Chief Online Officers, COVID-19, higher education, online learning

Bouchey, B., Gratz, E., \& Kurland, S. (2021). Remote student support during COVID-19: Perspectives of chief online officers in higher education. Online Learning, 25(1), 28-40. https://doi.org/10.24059/olj.v25i1.2481 


\section{Remote Student Support During COVID-19: Perspectives of Chief Online Officers in Higher Education}

As institutions of higher education continue to see online programming grow, inconsistencies and new trends in the structure and operations of online units become more critical to understand (Garrett, Legon, \& Fredericksen, 2019; Slimp, 2014). Among other key operations, colleges must provide high-quality and equitable support services to their online students including retention services (e.g., orientation, advising, coaching, course registration), student engagement (e.g., student activities, athletics, student government), student wellbeing (e.g., student counseling, health services, Title IX administration), and learning support (e.g., library, writing center, tutoring, career services, technology support) (Council of Regional Accrediting Commissions, 2011; Gratz, 2020). With the onset of the COVID-19 pandemic, as colleges quickly transitioned to universal remote learning, institutions needed to quickly identify strengths and areas of opportunity in the operations of their online student support services. In this paper, we provide perspectives from Chief Online Officers (COOs) of 31 higher education institutions on the COVID-19 transition to remote student supports, and explore how the pandemic may influence student supports at colleges in the future.

\section{Review of Relevant Literature}

The onset of COVID-19 and the ensuing pivot to remote instruction highlighted the preparedness, nimbleness, and flexibility of student support services, such as advising, tutoring, mental health support, and the overall infrastructure and readiness of an institution to work with students in a completely virtual environment (Doyle, 2020; Garrett et al., 2020; Ludeman \& Schreiber, 2020). The rapid pivots to remote teaching and learning added weight to previous literature that highlighted gaps in the support services offered to online students since now all students were learning virtually (Barr, 2014; Beaudoin, 2013; Brown, 2017; Forrester \& Parkinson, 2006; Hicks, 2016; Jones \& O’Shea, 2004; Luedtke, 1999; Mitchell, 2009; Ozoglu, 2009). This section outlines research into previous literature related to online student support services as compared to on-campus ones prior to the onset of COVID-19, as well as the impact of COVID-19 on remote teaching and learning, and the resulting need for remote student support. Moreover, this literature lays a foundation for understanding this study's interviews and its findings related to the impact of COVID-19 on online student support services overall.

\section{Online Student Support Services Pre-COVID-19}

In 2020, The International Association of Student Affairs and Services (IASAS) noted the importance of addressing the basic personal needs of students through a comprehensive set of outof-the-classroom student services. These services are designed to "enable and empower students to focus more intensely on their studies and personal growth, both cognitively and emotionally. They also should result in enhanced student learning outcomes and, consequently, higher retention and throughput (graduation) rates" (Ludeman \& Schreiber, 2020, p. 10). Providing high-quality and equitable student support services is not only important to student success, it is required by accrediting bodies (Barr, 2014; Council of Regional Accrediting Commissions, 2011; Currie, 2010). Smith (2005) argued that higher education institutions should provide an online student service that accomplish three key objectives: 
1. Identify the needs of its online and face-to-face learners.

2. Ensure that services are available when the learner wants them, rather than when the institution is ready to provide them.

3. Ensure that the virtual services are as good as or better than the in-person equivalents.

Leaders in student affairs and services see their roles as complements to the academic function whereby the support they offer to students lays the foundation for student success in higher education and beyond as students graduate and begin to contribute to society at-large (Ludeman \& Schreider, 2020). Importantly, student support services foster a sense of belonging for the students (Pelletier, 2020). Prior to the pandemic, most student support services were provided on-campus and since student support personnel tended to have less physical contact with online students, they may not have fully appreciated that particular population's expectations and perceptions (Forrester \& Parkinson, 2006). Research does confirm that institutions are not providing equitable student support services to online students, with the most significant gaps identified in student advising and counseling services (Barr, 2014; Brown, 2017; Cooper, Gin \& Brownell, 2019; Currie, 2010; Forrester \& Parkinson, 2006; Hicks, 2016; Luedtke, 1999). Arguing for a more textured context, Calhoun, Green, and Burke (2017) showed that this gap in service between face-to-face (F2F) and online students may be related to inadequate coverage of online student needs in student affairs preparation programs, suggesting a more systemic issue around service offered to online students in-practice. Interview questions in this study related to the support of online students sought to understand this gap more fully. Not surprisingly, the sudden shift to a fully virtual environment brought these gaps to the attention of the entire campus community and the higher education sector in general.

\section{The Impact of COVID-19 on Remote Teaching \& Learning}

With the currency of COVID-19, the research continues to grow on the overall impact of the coronavirus on higher educational institutions and its remote teaching, learning, and working environments. The report, CHLOE 5: The pivot to remote teaching in spring 2020 and its impact (Garrett et al., 2020), was one of the earliest studies conducted during the pandemic. The report highlighted that the pivot to emergency remote teaching and learning at colleges and universities consisted mostly of moving existing in-person courses into a virtual environment, learning management systems, real-time or recorded web conference meetings, and other internet-based tools at an average of 500 in-person courses per institution (Garrett et al., 2020). Many students and faculty were not familiar with learning in the virtual space, nor were they familiar with the available technology, software, or services and support for online students, identifying that nearly 50 percent of faculty, 51 percent of undergraduate students, and 27 percent of graduate students had never taught or experienced a fully online course prior to this point in time (Garrett et al., 2020). Chief online officers (COOs) identified plans to expand resources, such as upgrading software, adding capacity to campus networks, and purchasing equipment, as the most common ways to support the demands of the pivot. Lastly, CHLOE 5 reported that COOs indicated that higher education institutions were encountering new challenges with working, teaching, and learning from home related to lack of technology and inadequate bandwidth as well (Garrett et al., 2020), signaling the need for additional remote support structures for faculty, staff, and students alike. 
Remote student services. In addition to reports of broader institutional needs, recent surveys indicated that in light of the pandemic, students had and have a higher need for more support in the areas of financial aid and academic advising (Blankstein, Frederick, \& WolffEisenberg, 2020). And, as institutions and students face longer-term needs for remote teaching and learning, experts caution that students may need more support than ever as they face new stressors around their mental, social, and financial health (Blankstein et al., 2020; Burke, 2020; Hinton, 2020). Students were and are also experiencing life disruptions such as becoming ill, job loss, taking care of a sick family member, or home-schooling children (Blankstein et al., 2020; Educationdata.org, n.d.; Fishman \& Hiler, 2020; Garrett et al., 2020). In fact, students may find it even more difficult to stay motivated in their learning, presently, as they balance working obligations and family needs (Blankstein et al., 2020; Fishman \& Hiler, 2020; Hinton, 2020), suggesting a heightened need for scaffolding student support that can be offered virtually.

\section{Methods}

This article reports on the third in a series of semi-structured interviews that studied the evolving nature of online organizational structures. This set of interviews was conducted in May and June 2020, after the outbreak of the COVID-19 pandemic required colleges and universities to pivot to emergency remote teaching and student support services, and focused on student support services within higher educational online unit operations. The research question the interviews sought to answer was: How were higher educational institutions' online student support services affected during the pivot to remote learning necessitated by COVID-19?

\section{Participants and Sampling}

The participants were 31 chief online officers (COOs) from higher education institutions across the United States, recruited through the professional networks of the researchers and through the assistance of a prominent online education professional association. The research team used purposeful sampling according to Carnegie Classifications to ensure diversity of institutional type and geographic location within the sample. The criterion for participation was that the individual's position must fit the overall definition of a $\mathrm{COO}$, one who has the most decisionmaking authority over online programming (Garrett \& Legon, 2017). The participants represented 4-year public institutions $(n=17,55 \%)$, 4-year private institutions $(n=6,19 \%)$, 2-year public institutions $(n=5,16 \%)$, 2-year private institutions $(n=1,3 \%)$, and for-profit institutions $(n=2$, $6 \%$ ). While not in complete alignment for percentage make-up compared to the sector as a whole by the accounts of other data sources for online programming, the findings overall were consistent across this sample, making institution type insignificant. The geographical breakdown was 14 (45\%) from the Northeast, $6(19 \%)$ from the Midwest, 4 (13\%) from each of the West and Southwest, and $3(10 \%)$ from the Southeast; similarly the findings were consistent across geography as well.

\section{Instrumentation and Data Collection}

A semi-structured interview protocol was used to capture the essence of the constructs that led to the current structure and complexion of online student support services. This related to both the student support services offered through online units at the institution and the perceived implications and future of those services' or unit's offerings. The research team defined student support services as: The functions at the institution that take place outside of the classroom 
experience in which the students are active participants. This includes retention services (e.g., orientation, advising, coaching, course registration), student engagement (e.g., student activities, athletics, student government), student wellbeing (e.g., student counseling, health services, Title IX administration), and learning support (e.g., library, writing center, tutoring, career services, technology support) (Gratz, 2020). The guiding questions within the interview protocol focused on the current organizational structure of the unit offering online student support services and the benefits and consequences, institutional history, and any upcoming modifications of this structure.

Interviews lasted approximately 60 minutes and were conducted via Zoom webconferencing. Each of the one-on-one interviews was conducted by one of the six members of the research team. Before the interviews, the principal investigators provided a qualitative interview guide and the research team met to discuss interview procedures to establish standards and minimize bias when conducting interviews. We acknowledge that a limitation inherent to qualitative research is its reliance on individual researcher interviewing skills-which is only more pronounced when having six researchers, as in this study. Despite the efforts of the research team to norm, provide tools to reduce the level of bias, and standardize the approach used by each interviewer, this limitation cannot be fully avoided.

\section{Data Analysis}

Verbatim interview transcripts were generated and member-checked by each participant, then de-identified and assigned a participant number known only to the principal investigators for the study. Content analyses were performed in parallel by two members of the research team, who each read, organized, and classified participant comments into codes (Creswell, 2013). Once this stage was complete, an internal audit was conducted in which the two sets of codes were compared to validate and establish one set of themes. Total code counts were generated by counting each time participant comments corresponded with a particular theme.

\section{Results}

Most participants (26, or 84\%) mentioned COVID-19 in their responses. Of those 26 respondents, $92 \%$ explicitly mentioned COVID-19's influence on themselves as the COO or upon student services, while the remaining $8 \%$ only briefly mentioned COVID-19 and did not connect the pandemic directly to issues of access and equity around student services. Across all 31 interviews, five major themes arose from the data: 1) virtual services provide access for all students, 2) expansion of student services to remote delivery because of COVID-19, 3) existing online services enable a more seamless institutional pivot to remote delivery, 4) online units and COOs are integral to institutional pivots to remote delivery, and 5) curiosity about the future of online student services. Below, we discuss each of the five themes in more detail.

\section{Virtual Services Provide Access for All Students}

One of the most prevalent results of this study was the shift in emphasis to more access and equity in online student support services across the participants' institutions. Twenty-six participants mentioned that online students had less access to student support services than their face-to-face (F2F) counterparts before COVID-19, regardless of tuition and fee differentials. One ongoing challenge noted by COOs was institutional leadership distinguishing online students from F2F students, which meant that they needed to prove that online services and support were necessary for such a small subset of students. Yet at all 31 institutions, COVID-19 shifted online 
support services to all students. Most student services offerings (advising, coaching, learning support, library, counseling, financial aid, health and mental health, and clubs and associations) were now offered through departments that served all students, regardless of the modality of the program, while a few services (most often student success coaching and advising) remained specialized for online versus F2F students.

One of the most significant findings of this study and the COVID-19 experience is that institutional leaders have realized that providing online student support serves all students, not only online students. Nearly half (48\%) of interviewees addressed this mindset shift. Participant 24 compared designing for online to universal design: "We really didn't have a whole lot for the online students....It's kind of like universal design with accessibility....If we're designing for the online student, it's going to make it a better experience for all of our students." This emphasis on serving all students was also evident in this statement:

When all of a sudden you have to serve your students remotely, you move more quickly to develop those resources because you understand that all students need them, whereas before you might say, "Well, you can access these on campus, you really need to be here to do that." So COVID, has given us an incredible boost in terms of online student support services. (Participant 15)

Another participant elaborated on the differing mindsets that resulted from the response to COVID-19:

We've chosen to stick with ensuring that our main campus services...that we have are fully accessible to all of our students. And I think pre- v. post-COVID, we are even more internally aware of that need. One of the silver linings in having gone through what we've gone through is that the units that were maybe hesitant to really try to think outside the box to build capacity for meeting students in a more virtual way have had to and have successfully done so. We've certainly had bumps in the road this spring. But by and large, all of our units across our campus have stepped up in amazing ways to serve the needs of our students. (Participant 14)

That participant went on to address student support services overall and what institutional leaders learned through COVID-19. "[Student services] was important pre-COVID, and we've seen it's taken on a whole new dimension and importance...when you're not in person, you've got to be more intentional about these...supports. Ultimately,...it's going to benefit all our students."

Another participant discussed the balance of providing synchronous and asynchronous services to all students:

The other aspect...from COVID...is the need for more student services virtually... A lot of what we do in online is asynchronous, and definitely has its place, its value. There's value in synchronicity as well. And so, find the right balance...that can be really important for us that applies not only to teaching, learning, but also to services. And what this is going to do... is that every student can benefit from these online services, not just students that are going to be $100 \%$ remote. (Participant 20)

Participant 16 speculated that the provision of student services will go through a transformation in order to serve all students, regardless of their modality: "If you haven't brought the support services online, how are you really taking care of our students? So, I suspect this whole thing is going to make us all rethink how we do support." 


\section{Expansion of Student Services to Remote Delivery Because of COVID-19}

Due to COVID-19, student services suddenly expanded to remote delivery. Almost half (42\%) of participants discussed this pivoting process, their role in the pivot, and its necessity for all students' access.

Obviously, every service is only happening virtually, whether it's through email or through Zoom...Zoom advising appointments, Zoom meetings with admissions, all different sorts of opportunities... Just like on the academic side, we're telling faculty to be prepared [to teach online] at any given time... [Student services are] going to have some hard decisions on what they're going to do and how they're better going to cater to people. (Participant 31)

The switch to remote delivery forced departments and staff to be creative and figure out how to provide services virtually.

What's really been helpful is that given how we were all kind of thrown off the deep end of the pool, into...working remote and teaching and learning remote this spring, there was a lessening of the expectations. That was "Do the best you can." People had to try...they've now gotten over the hurdle and the initial step of "We've never tried that-we don't know that it can work." They've... seen what's possible. (Participant 14)

Moreover, about a third (32\%) of participants discussed how the pivot to online opened up new access to student services for online students.

Before COVID, the writing center had its [web]pages that have a whole lot of stuff that people could access whether they were F2F or online students, but they weren't doing virtual tutoring. After COVID, they started doing virtual tutoring. So all students, including online students, had access to those services, at least during the crisis. They weren't excluding either group. (Participant 1)

Participant 14 also noted "Student services is one of those areas where the writing center went fully virtual and it's working. Students are making appointments and getting support...They're not meeting in person...but people are learning to use the tools that are available."

\section{Existing Online Services Made Pivoting to Emergency Remote Delivery More Seamless}

While all teaching and learning support was pivoting to remote because of the COVID-19 pandemic, some participants (23\%) said that previously existing online support services allowed their entire university to pivot to remote delivery more easily than their peer institutions. As Participant 18 stated, "Virtual services now are becoming available. . . Now they were able to pivot and offer all of those services more widely [to the entire student body. Services] were there and available to all the students; before it just wasn't as utilized."

Preexisting online student support services allowed all students to access them, and departments were more easily able to expand their services to the entire student body.

We can scale up our online program really quickly because the students have access to all of those other units that are already serving students. And so, with this recent change to remote learning, all of our students switched online within 5 days, but they were still able to access all the student support services that they needed. So, we scaled up our online program really quickly, really fast. (Participant 3 ) 
Another participant offered a similar perspective:

Those lessons learned in how we can function. . . [and] can support students in the virtual environment, we've proven that we can do it on short notice, and it hasn't been ideal. We've had to use duct tape and take some shortcuts here and there at times. But we've learned a lot. It's really going to condition us to be able to continue innovating. (Participant 14)

\section{Online Units and COOs Integral to Institutional Pivots to Remote Delivery}

Throughout the interviews, most participants (77\%) discussed collaborating and building relationships between their unit and other departments' leaders and staff to ensure that student support services could be offered to all students during the pivot. Nearly half (45\%) explicitly discussed the role they and their team played during COVID-19. The COO and online units have become critical resources to enable campus-based departments, staff and administrators, and faculty to operate remotely. Additionally, three participants discussed the opportunity to build new relationships with campus-based peers and colleagues as a result of COVID-19. Participant 6 commented, "COVID 19 was very interesting, that a lot of people looked at us and said 'Wow!' But it wasn't wow, it was just business as usual, but on a much larger context." Another participant discussed their unit's role in developing a laptop program for the students, as an example of this newfound collaboration:

Suddenly we're online and our students are like "I need to get an incomplete because I can't do it online." One thing we . . . did was work very hard to get a laptop program in place ... Every student who is taking six credits or more will have a laptop provided to them by the college. (Participant 25)

\section{Curiosity About the Future of Online Student Services}

About a third of participants (35\%) expressed curiosity about what might occur to student support services after COVID-19. These speculations were primarily centered around whether more robust service offerings would stay in place and whether there would be less resistance to online programming and services at their institutions and across the higher education sector.

Continuation of online student services. Some participants (19\%) expressed curiosity about whether the more robust online student services realized during COVID-19 would continue after students returned to campus and whether the experience with remote offerings in student support would make these offerings more efficient. This can be seen in statements like: "I am really hoping this will really be the forward momentum that will stay and things will change that will cater more [to all students]" (Participant 24). Another participant observed, "COVID has helped a lot of institutions realize ... It is possible to do it this way...[and] do it well this way. And so why would we not continue to offer that if it results in increased efficiencies and increased effectiveness?" (Participant 15) A third participant said:

How do we make sure we take the lessons learned, and . . the aspects of how we have shifted our processes, procedures, operations in light of COVID-19? How do we make sure we institutionalize those gains - the things that we've iterated on and taken steps forand that we don't go backwards? (Participant 13)

Reduced resistance to online programs and online support. Some participants $(16 \%)$ expressed curiosity about whether there would be less resistance to online programming after COVID-19, or perhaps even more online support. Participant 10 believed: “There's a new 
connection with not only our different departments now going online, but there's a connection to them so that we're not working in silos. We can understand their world better. They can understand ours." Participant 24 noted the potential change in providing training and services, "There's going to be less of a barrier to continue to offer [online trainings]. We will still offer the face-to-face..., but we can also continue to offer these remote sessions so we can reach people who can't come to campus." Additionally, Participant 13 considered what had been learned overall in regard to online support services and having to offer them remotely during COVID-19. "Three to five years from now, as we look back, we're going to have much more robust student services across the board, much more flexible... [and] accessible...because of the lessons we've learned, the hard steps we've taken."

These findings related to online student support after the shift to remote operations because of COVID-19 illuminated the gaps between the student support services offered to face-to-face (F2F) students and their fully online counterparts. The forced shutdowns and the ensuing pivot to emergency remote operations closed these gaps rather quickly, thereby increasing access to these critical support services, forging new relationships between COOs and their units, and setting the foundation for possible permanent improvements to online and remote student support services. As institutions resume campus-based operations, critical questions emerge about what practices should be continued, discontinued, and leveraged.

\section{Discussion}

Overall, findings suggest that the unanticipated need to pivot all campus operations to an emergency remote setting led institutions of higher education to rapidly identify gaps between student support services offered to face-to-face versus fully online students, and to take measures to close those gaps quickly. Interviewee perspectives led to two key insights. First, offering student support services virtually not only supports online students, but also supports campus-based students, whether they are on-campus or otherwise. In other words, virtual student services provide access to all students. Second, institutions that already had strength in online programming before the shutdowns also seemed advantaged during the pivot to emergency remote operations. These advantages stemmed not only from institutional knowledge of online programming, but also from the virtual operations in which many online units operated, which illuminated the role of COOs as key enablers of smooth shifts to remote operations.

\section{Virtual Supports Help All Students}

Overall, interview participants indicated that the response to the virus had improved support for online students as well as for face-to-face (F2F) students. These findings add to the literature by illuminating the wide gap between the student support services offered to face-to-face (F2F) students and those offered to fully online students (Barr, 2014; Beaudoin, 2013; Brown, 2017; Forrester \& Parkinson, 2006; Hicks, 2016; Jones \& O’Shea, 2004; Luedtke, 1999; Mitchell, 2009; Ozoglu, 2009). As institutions around the globe continue to respond to the pandemic through longer-term reliance on remote teaching and learning, the support of students at-a-distance becomes ever more critical to understand and cultivate (Burke, 2020; Fishman \& Hiler, 2020).

The long-term expansion of online and remote access to student support is a critical point of reflection for institutions of higher education. The modern college student is digitally versed and reliant on the use of technology, so we need to investigate the efficacy of continuing to offer 
expanded access to student support, especially in light of the additional needs students may have as they continue to experience the stressors and new tensions of COVID-19 (Burke, 2020; Fishman \& Hiler, 2020). It perhaps challenges the notion on the distinction between modality in postsecondary schooling (i.e., the spectrum from face-to-face to online learning); prompting the key question if the needs of campus-based and online students are significantly different.

As institutions continue to compete for students, instead of primarily focusing attention on student support services for on-campus students, it may be equally important to ensure that students can access support and services in the mode (F2F or online) that is most familiar or helpful to them, especially considering their changing demographics. Contemporary institutions of higher education may be better off thinking about computer server space, rather than space for a new student lounge, for example. Importantly, this potential shift in mindset challenges institutions to carefully consider how to build levels of community in a virtual setting, as well as how they support their students' social and emotional learning.

\section{Pivoting on an Online Foundation}

Consistent with recent research, findings also suggested that institutions which had heavily invested in online programming prior to COVID-19 found it easier to pivot to online and remote operations (Garrett et al., 2020). This further highlights the need to more fully integrate the knowledge and expertise of COOs and their units across institutions. As participants reflected on new collaborations forged by the pandemic shutdowns and the ensuing pivot to emergency remote operations, they thought that isolating expertise in online operations among a single set of people was not good for institutional efficiency, and would limit the extent to which the college could internalize lessons from the pandemic and institutionalize new practices. Instead of institutions relying on a small group of staff working exclusively to support fully online students, they should find ways to leverage these innovative online partners and continue to modernize operations and uncover new efficiencies. Given the long-term nature of the pandemic, it makes sense to formally evaluate the efficiency of spreading the knowledge of the $\mathrm{COO}$ and their units across the institution, regardless of modality of service or academic program. Along the same lines, institutions may be served by investigating the siloed nature of their online units (as applicable) to build capacity and reduce risk of isolating online knowledge, skills, and abilities to one unit (Garrett et al., 2020).

\section{Other Implications for Research and Practice}

This study represents a first step to understanding the provision of online support services to all students. A follow-up study specifically designed to measure online student support before, during, and after COVID-19 would uncover the long-term provision of these services and identify the measures that are in place to determine efficacy and return on investment. Further research into student consumption of student services and their preferences could yield a balanced portfolio of F2F and online student support services aligned to the modern student demographic and college campus. Using a quantitative instrument to measure these areas among a larger sample population would provide texture to this study and increase the fidelity of the findings.

In addition to formal research, institutions should also gather and reflect upon internal data on student supports. It is critical for institutions to formally evaluate all students' access to student support services, not just as the pandemic continues, but also when campus-based operations resume. With online enrollment continuing to rise, and the student demographic becoming more diverse, institutions must adapt to digital and virtual ways of supporting students, even for those 
living in dormitories. Providing equal access to student support services, regardless of modality, seems to be an ethical imperative for institutions of higher education, but it may also result in advantages as colleges and universities compete for students. Based on experiences during the pandemic of 2020, it appears that most student support services can be offered effectively at-adistance.

Moreover, it remains important for each institution to take the time to express, document, and act upon the findings from this pivot to emergency remote operations. This pandemic has taught many lessons to people across the globe; for institutions of higher education, it has highlighted the importance of nimble operations and hiring faculty and staff who are adept at change management and those that keep up with the evolving nature of education. Institutions that take steps now to increase their resilience, through faculty and staff development, in their instructional delivery models, and in the support of their students, no matter the modality, can manage their risk during other types of shutdowns as well as meet the needs of the changing student body. The lasting impact of this pandemic will be to strengthen institutions that leverage the expertise of their COOs and their staff; it may weaken those that return to normal once the virus passes.

\section{Acknowledgements}

The authors of this article would like to thank the members of the seed grant committee at National Louis University for their generous support of our study. Each of the authors would also like to thank their institutions for their support of the research and writing time spent on this important set of findings related to COVID-19's influence on online student support services. Furthermore, the authors would like to acknowledge the rest of the underlying study's full research team, Michael Reis, Monica Simonsen, and Maricel Lawrence. Importantly, the authors and the underlying study's full research team would like to thank the Online Learning Consortium for offering the program that was the genesis for this research collaborative and to the CHLOE researchers for their partnership and advisement during the planning and implementation of this study of the evolving nature of online education in America. 


\section{References}

Barr, B. (2014). Identifying and addressing the mental health needs of online students in higher education. Online Journal of Distance Learning Administration, 17(2). https://www.westga.edu/ distance/ojdla/summer172/barr172.html

Beaudoin, M. (2013). Institutional leadership. In M. G. Moore (Ed.), Handbook of distance education ( $3^{\text {rd }}$ ed., pp. 467-480). New York, NY: Routledge.

Blankstein, M, Frederick, J. K., \& Wolff-Eisenberg, C. (2020, June 25). Student experiences during the pandemic pivot. Ithaka $S+R$. DOI: https://doi.org/10.18665/sr.313461

Brown, B. L. (2017). Higher education distance advising in the $21^{\text {st }}$ century: Distance learning students' and advisors' perceptions (Doctoral dissertation). https://digitalcommons.odu.edu/cgi/viewcontent.cgi?article $=1028 \&$ context $=$ stemps_etds

Burke, L. (2020, October 27). Moving into the long-term. InsiderHigherEd. Retrieved from https://www.insidehighered.com/digital-learning/article/2020/10/27/long-term-onlinelearning-pandemic-may-impact-students-well

Calhoun, D. W., Green, L. S., \& Burke, P. (2017). Online learners and technology: A gap in higher education and student affairs professional preparation. Quarterly Review of Distance Education, 18(1), 45-61.

Cooper, K. M., Gin, L. E., \& Brownell, S. E. (2019). Diagnosing differences in what introductory biology students in a fully online and an in-person biology degree program know and do regarding medical school admission. Advances in Physiology Education, 43(2), 221-232.

Council of Regional Accrediting Commissions. (2011). Interregional guidelines for the evaluation of distance education. National Council for State Authorization Reciprocity Agreements. https://nc-sara.org/sites/default/files/files/2019-08/C-RAC\%20Guidelines\%282011\%29.pdf

Creswell, J. W. (2013). Qualitative inquiry \& research design: Choosing among five approaches $\left(3^{\text {rd }}\right.$ ed.). Thousand Oaks, CA: SAGE.

Currie, N. S. (2010). Virtual counseling for students enrolled in online educational programs. Educational Considerations, 37(2), 22-26.

Doyle, J. (2020, April 7). Fostering student success outside of online classrooms. Inside Higher Ed. https://www.insidehighered.com/advice/2020/04/07/whats-role-student-affairs-andacademic-support-staff-when-most-students-arent

Educationdata.org. (n.d.). Online education statistics. https://educationdata.org/online-educationstatistics/

Fishman, R., \& Hiler, T. (2020, September 2). New polling from new America \& third way on COVID-19's impact on current and future college students. Third Way. https://www.thirdway.org/memo/new-polling-from-new-america-third-way-on-covid-19simpact-on-current-and-future-college-students

Forrester, G., \& Parkinson, G. (2006). "Mind the gap": The application of a conceptual model to investigate distance learners' expectations and perceptions of induction. Issues in Educational Research, 16(2), 152-170. 
Garrett, R. \& Legon, R. (2017). CHLOE: The changing landscape of online education. Quality Matters. https://www.qualitymatters.org/sites/default/files/research-docs-pdfs/CHLOE-FirstSurvey-Report.pdf

Garrett, R., Legon, R., \& Fredericksen, E. E. (2019). CHLOE 3: Behind the numbers. Quality Matters. https://www.qualitymatters.org/qa-resources/resource-center/articlesresources/CHLOE-3-report-2019

Garrett, R., Legon, R., Fredericksen, E. E., \& Simunich, B. (2020). CHLOE 5: The pivot to remote teaching in spring 2020 and its impact. Quality Matters. https://www.qualitymatters.org/qaresources/resource-center/articles-resources/CHLOE-5-report-2020

Gratz, E. (2020, March 2). Thinking about the dimensions of online education. CORAL Collaborative Blog. https://www.coralcollaborative.com/post/thinking-about-thedimensions-of-online-education.

Hicks, J. M. (2016). Perceptions and attitudes of students in an online allied health program regarding academic advising methods (Doctoral dissertation). https://search.proquest.com/docview/1931104440

Hinton, V. P. (2020, August 18). Facing the disconnect: College students and online learning. Digital Promise. https://digitalpromise.org/2020/08/18/facing-the-disconnect-collegestudents-and-online-learning/

Jones, N., \& O'Shea, J. (2004). Challenging hierarchies: The impact of e-learning. Higher Education, $48,379-395$.

Ludeman, R. B. \& Schreiber, B. (2020). Student affairs and services in higher education: Global foundations, issues, and best practices. (3rd ed.). International Association of Student Affairs and Services. http://iasas.global/wpcontent/uploads/2020/07/200707_DSW_IASAS_final_web.pdf

Luedtke, C. B. (1999). Distance education programs in Texas community \& technical colleges: Assessing student support services in a virtual environment (Doctoral dissertation). https://digital.library.txstate.edu/handle/10877/3532

Mitchell, R. L. G. (2009). Online education and organizational change. Community College Review, 37(1), 81-101. doi:10/1177/0091552109338731

Ozoglu, M. (2009). A case study of learner support services in the Turkish open education system (Doctoral dissertation). https://digitalcommons.usu.edu/etd/410/

Pelletier, K. (2020, August 25). Create better student support structures for remote learning. Ed Tech. https://edtechmagazine.com/higher/article/2020/08/create-better-student-supportstructures-remote-learning

Slimp, M. (2014). Trends in distance education - What college leaders should consider [White paper]. Instructional Technology Council. https://intc.memberclicks.net/assets/docs/TrendsinDistanceEducationNov2014FINALWEBV ERSION.pdf

Smith, B. (2005). Online student support services. Community College Journal, 76(2), 26-29. 